\title{
THERMODYNAMIC STABILITY RELATIONS IN THE C-H-O SYSTEM
}

\author{
Ilie Fishtik \\ *Department of Chemical Engineering, Worcester Polytechnic Institute, Worcester, MA, 01609, USA \\ E-mail: ifishtik@wpi.edu
}

In memory of Ion Vatamanu: a poet, a scholar and a man of great wisdom

\begin{abstract}
Thermodynamic stability relations in the C-H-O system are analyzed employing a recently developed approach to the stability of chemical species in multiple chemical reaction systems. The approach is based on a new quantitative definition of the overall stability of chemical species in terms of stoichiometrically unique reactions. Analytical equations for the overall stability of the species are generated and shown to be a useful and simple means to rationalize and predict the system's behavior as a function of temperature, pressure and composition.
\end{abstract}

\section{Introduction}

Chemical thermodynamics is an invaluable tool in determining the feasibility and optimal conditions of chemical reaction processes [1,2]. The evaluation of the equilibrium composition is now accomplished employing commercial computer software [3]. Due to a large number of independent variables that govern the equilibrium composition, however, namely, temperature, pressure and composition, it is often difficult to comprehend and rationalize the overall behavior of the system based on a large numeric output. In this respect, simple stoichiometric and graphical stability relations in complex chemical reaction systems can provide a concise picture of the expected behavior of the system as a function of the variables. Thus, the carbon deposition boundary at a given temperature and pressure may be graphically depicted employing the well-known C-H-O ternary diagram [4-6]. These diagrams, however, are still constructed based on numerical evaluation of the equilibrium compositions of the system for various values of the variables.

We have recently developed a new approach to the stability relations in multiple chemical reaction systems [7-8]. Our approach not only results in analytical expressions for stability relations of the species but, concomitantly, provides a remarkable interpretation and comprehension in terms of stoichiometric uniqueness of chemical reactions. In this contribution, we apply the overall stability approach to the analysis of the C-H-O system that is pertinent to steam and carbon dioxide reforming of methane as well as gasification of carbon.

\section{Theoretical Considerations}

Our overall stability approach is in fact the generalization of the fundamental thermodynamic principle according to which a single chemical reaction $\rho$ is thermodynamically feasible (spontaneous, favorable) depending on the sign of its Gibbs free energy change, $\Delta G_{\rho}$ (or, affinity). That is, if $\Delta G_{\rho}$ is negative, the reaction should proceed from left to right, and, vice versa, if $\Delta G_{\rho}$ is positive, the reaction should proceed from right to left. Alternatively (and equivalently) this principle may be formulated in terms of species rather than reactions. Thus, if $\Delta G_{\rho}<0$, the reactants are unstable (consumed) while the products are stable (formed). Similarly, if $\Delta G_{\rho}>0$, the reactants are stable (formed) and products are unstable (consumed). It is this equivalent formulation that allows a rigorous generalization of a single reaction feasibility principle to multiple chemical reactions systems.

Below we present a succinct summary of the overall stability approach [7.8]. Let $\mathrm{B}_{i}(i=1,2, \ldots, n)$ be a set of chemical species involved in a multiple chemical reaction process. Let $\bar{G}_{i}(i=1,2, \ldots, n)$ be the partial Gibbs free energies of the species in an initial (before reaction) state. Let the same quantities at equilibrium (after reaction) state be $\bar{G}_{i}^{e q}(i=$ $1,2, \ldots, n)$. For each species we define a quantitative measure of stability, $\Sigma_{i}=\bar{G}_{i}-\bar{G}_{i}^{e q}(i=1,2, \ldots, n)$, referred to as the overall stability, such that

i) species $\mathrm{B}_{i}$ is stable if $\Sigma_{i}<0$

ii) species $\mathrm{B}_{i}$ is unstable if $\Sigma_{i}>0$

iii) species $\mathrm{B}_{i}$ is at equilibrium if $\Sigma_{i}=0$

The overall stabilities may be evaluated employing a stoichiometrically and thermodynamically constrained minimization procedure similar to that used in least square method that has been in detail presented in our previous 
publications $[7,8]$. Here we present only the final result in terms of stoichiometrically unique response reactions (RERs) [9].

$$
\Sigma_{i}=\frac{1}{\Delta} \sum_{\rho} \gamma_{\rho}^{2} v_{\rho i} \Delta G_{\rho} ; i=1,2, \ldots, n
$$

where

$$
\Delta=\frac{1}{m} \sum_{\rho} \sum_{i=1}^{n} \gamma_{\rho}^{2} v_{\rho i}^{2}
$$

and where $m$ is the number of linearly independent reactions, $v_{\rho i}$ is the stoichiometric coefficient of species $\mathrm{B}_{i}$ in RER $\rho$ and $\Delta G_{\rho}$ are the Gibbs free energy changes of RERs. In deriving eq 1 the convention of stoichiometrically distinct RERs has been employed, i.e., stoichiometrically equivalent RERs are considered as one RER with a lumped stoichiometric factor $\gamma_{\rho}^{2}[8]$.

Since $\Delta$ and $\gamma_{\rho}^{2}$ in eq 1 are necessarily positive quantities the sign of the overall stability $\Sigma_{i}$ are entirely determined by the sign of the products $v_{\rho i} \Delta G_{\rho}$. This property of $\Sigma_{i}$ allows a clear physicochemical interpretation: namely, if $\Delta G_{\rho}<0$ then the RER $\rho$ proceeds from the left to the right, which in turn means that the reactants $\left(v_{\rho i}<0\right)$ in this particular RER are unstable (consumed) while the products $\left(v_{\rho i}>0\right)$ are stable (formed). Similarly, if $\Delta G_{\rho}>0$ then the RER $\rho$ proceeds from the right to the left and, hence, the reactants $\left(v_{\rho i}<0\right)$ are stable (formed) while the products $\left(v_{\rho i}>0\right)$ are unstable (consumed). The total overall stability of a species is a sum over the RERs involving this particular species.

\section{RERs in the C-H-O System}

Since the overall stabilities of the species are expressed in terms of RERs we consider first the generation of a complete set of RERs along with their stoichiometric factors and Gibbs free energy changes [8]. Our starting point is the formula matrix

$$
\begin{aligned}
& \text { C } \mathrm{H} \mathrm{O}
\end{aligned}
$$

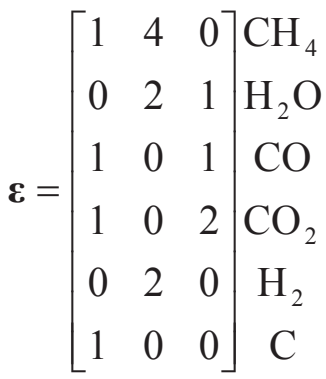

Rank $\boldsymbol{\varepsilon}=3$ and, hence, any $3+1=4$ species define a RER [9]. Four species may be selected from a total of six species in 6!/4!/2! = 15 ways, i.e., the total number of RERs does not exceed 15. For instance, selecting $\mathrm{CH}_{4}, \mathrm{H}_{2} \mathrm{O}, \mathrm{CO}$, and, $\mathrm{C}$ results in the RER [8]

$$
\begin{aligned}
& \rho\left(\mathrm{CH}_{4}, \mathrm{H}_{2} \mathrm{O}, \mathrm{CO}, \mathrm{C}\right):\left|\begin{array}{cccc}
1 & 4 & 0 & \mathrm{CH}_{4} \\
0 & 2 & 1 & \mathrm{H}_{2} \mathrm{O} \\
1 & 0 & 1 & \mathrm{CO} \\
1 & 0 & 0 & \mathrm{C}
\end{array}\right|=-2 \mathrm{CH}_{4}+4 \mathrm{H}_{2} \mathrm{O}-4 \mathrm{CO}+6 \mathrm{C} \\
& =2\left(-\mathrm{CH}_{4}+2 \mathrm{H}_{2} \mathrm{O}-2 \mathrm{CO}+3 \mathrm{C}\right)=0
\end{aligned}
$$

with a stoichiometric factor equal to 2 . Not all of the RERs, however, are stoichiometrically distinct. For instance, the following RERs are, in fact, stoichiometrically equivalent 


$$
\begin{aligned}
& \rho\left(\mathrm{CH}_{4}, \mathrm{CO}, \mathrm{CO}_{2}, \mathrm{C}\right):\left|\begin{array}{cccc}
1 & 4 & 0 & \mathrm{CH}_{4} \\
1 & 0 & 1 & \mathrm{CO} \\
1 & 0 & 2 & \mathrm{CO}_{2} \\
1 & 0 & 0 & \mathrm{C}
\end{array}\right|=4\left(0 \mathrm{CH}_{4}-2 \mathrm{CO}+\mathrm{CO}_{2}+\mathrm{C}\right)=0 \\
& \rho\left(\mathrm{H}_{2} \mathrm{O}, \mathrm{CO}, \mathrm{CO}_{2}, \mathrm{C}\right):\left|\begin{array}{cccc}
0 & 2 & 1 & \mathrm{H}_{2} \mathrm{O} \\
1 & 0 & 1 & \mathrm{CO} \\
1 & 0 & 2 & \mathrm{CO} \\
1 & 0 & 0 & \mathrm{C}
\end{array}\right|=-2\left(0 \mathrm{H}_{2} \mathrm{O}-2 \mathrm{CO}+\mathrm{CO}_{2}+\mathrm{C}\right)=0 \\
& \rho\left(\mathrm{H}_{2} \mathrm{O}, \mathrm{CO}, \mathrm{CO}_{2}, \mathrm{C}\right):\left|\begin{array}{lllc}
1 & 0 & 1 & \mathrm{CO} \\
1 & 0 & 2 & \mathrm{CO} \\
0 & 2 & 0 & \mathrm{H}_{2} \\
1 & 0 & 0 & \mathrm{C}
\end{array}\right|=-2\left(0 \mathrm{H}_{2}-2 \mathrm{CO}+\mathrm{CO}_{2}+\mathrm{C}\right)=0
\end{aligned}
$$

As may be seen that, the stoichiometric coefficients of $\mathrm{CH}_{4}, \mathrm{H}_{2} \mathrm{O}$ and $\mathrm{H}_{2}$ are equal to zero and, hence, all of these three RERs essentially represent the following RER

$$
2 \mathrm{CO}=\mathrm{C}+\mathrm{CO}_{2}
$$

Table 1

A Complete Set of RERs and their Stoichiometric Factors for the System C-H-O. Gibbs Free Energy Changes were Evaluated at $P=1$ atm and Equimolar Composition of the Gas Phase Using Data from

Table 2

\begin{tabular}{llll} 
RERs & $\gamma_{\rho}^{2}$ & \multicolumn{2}{c}{$\Delta G_{\rho}, \mathrm{kJ} / \mathrm{mol}$} \\
& & $T=500^{0} \mathrm{~K}$ & $T=1200^{0} \mathrm{~K}$ \\
$\rho_{1}=-\mathrm{CH}_{4}-\mathrm{H}_{2} \mathrm{O}+\mathrm{CO}+3 \mathrm{H}_{2}=0$ & 1 & 83.15 & -109.39 \\
$\rho_{2}=-\mathrm{CH}_{4}-2 \mathrm{H}_{2} \mathrm{O}+\mathrm{CO}_{2}+4 \mathrm{H}_{2}=0$ & 1 & 63.04 & -106.18 \\
$\rho_{3}=-\mathrm{CH}_{4}-\mathrm{CO}_{2}+2 \mathrm{CO}+2 \mathrm{H}_{2}=0$ & 1 & 103.26 & -112.59 \\
$\rho_{4}=-\mathrm{CH}_{4}-3 \mathrm{CO}_{2}+4 \mathrm{CO}+2 \mathrm{H}_{2} \mathrm{O}=0$ & 1 & 143.49 & -119.01 \\
$\rho_{5}=-\mathrm{H}_{2} \mathrm{O}-\mathrm{CO}+\mathrm{CO}_{2}+\mathrm{H}_{2}=0$ & 1 & -20.11 & 3.20 \\
$\rho_{6}=-3 \mathrm{C}-2 \mathrm{H}_{2} \mathrm{O}+2 \mathrm{CO}+\mathrm{CH}_{4}=0$ & 1 & 87.61 & -47.39 \\
$\rho_{7}=-2 \mathrm{C}-2 \mathrm{H}_{2} \mathrm{O}+\mathrm{CO}_{2}+\mathrm{CH}_{4}=0$ & 4 & 10.58 & 8.07 \\
$\rho_{8}=-\mathrm{C}-2 \mathrm{H}_{2}+\mathrm{CH}=0$ & 6 & -26.23 & 57.13 \\
$\rho_{9}=-\mathrm{C}-\mathrm{CO}_{2}+2 \mathrm{CO}_{4}=0$ & 6 & 77.03 & -55.46 \\
$\rho_{10}=-\mathrm{C}-\mathrm{H}_{2} \mathrm{O}+\mathrm{CO}^{2} \mathrm{H}_{2}=0$ & 1 & 56.92 & -52.26 \\
$\rho_{11}=-\mathrm{C}-2 \mathrm{H}_{2} \mathrm{O}+\mathrm{CO}_{2}+2 \mathrm{H}_{2}=0$ & 1 & 36.81 & -49.06
\end{tabular}

Upon generating all RERs and thus their stoichiometric factors, it is found that the set of stoichiometric factors may be simplified by a factor of two. For instance, the stoichiometric factors of the above three RERs are, respectively, equal to 2, 1 and 1 which gives a squared sum $\gamma_{\rho}^{2}$ equal to 6 .

Table 2

Gibbs Free Energy Changes (kJ/mol) of the RERs (Table 1) in the System C-H-O for an Ideal Gas - Pure Solid Phase Model

$$
\Delta G_{1}=234.36-0.25634 T-\frac{4828.4}{T}+2 R T \ln \frac{P}{P_{0}}+R T \ln \frac{x_{\mathrm{CO}} x_{\mathrm{H}_{2}}^{3}}{x_{\mathrm{CH}_{4}} x_{\mathrm{H}_{2} \mathrm{O}}}
$$




$$
\begin{aligned}
& \Delta G_{2}=204.32-0.22699 T-\frac{7201.2}{T}+2 R T \ln \frac{P}{P_{0}}+R T \ln \frac{x_{\mathrm{CO}_{2}} x_{\mathrm{H}_{2}}^{4}}{x_{\mathrm{CH}_{4}} x_{\mathrm{H}_{2} \mathrm{O}}^{2}} \\
& \Delta G_{3}=264.39-0.28568 T-\frac{2455.0}{T}+2 R T \ln \frac{P}{P_{0}}+R T \ln \frac{x_{\mathrm{CO}^{2}}^{2} x_{\mathrm{H}_{2}}^{2}}{x_{\mathrm{CH}_{4}} x_{\mathrm{CO}_{2}}} \\
& \Delta G_{4}=324.31-0.34431 T+\frac{2357.7}{T}+2 R T \ln \frac{P}{P_{0}}+R T \ln \frac{x_{\mathrm{CO}^{4}}^{4} x_{\mathrm{H}_{2} \mathrm{O}}^{2}}{x_{\mathrm{CH}_{4}} x_{\mathrm{CO}_{2}}^{3}} \\
& \Delta G_{5}=-30.032+0.029343 T-\frac{2373.4}{T}+R T \ln \frac{x_{\mathrm{CO}_{2}} x_{\mathrm{H}_{2}}}{x_{\mathrm{H}_{2} \mathrm{O}} x_{\mathrm{CO}}} \\
& \Delta G_{6}=178.31-0.17610 T+\frac{2017.9}{T}+R T \ln \frac{P}{P_{0}}+R T \ln \frac{x_{\mathrm{CO}^{2}}^{2} x_{\mathrm{CH}_{4}}}{x_{\mathrm{H}_{2} \mathrm{O}}^{2}} \\
& \Delta G_{7}=10.724-0.002615 T+\frac{581.29}{T}+R T \ln \frac{x_{\mathrm{CO}_{2}} x_{\mathrm{CH}_{4}}}{x_{\mathrm{H}_{2} \mathrm{O}}^{2}} \\
& \Delta G_{8}=-96.800+0.11219 T+\frac{3891.6}{T}-R T \ln \frac{P}{P_{0}}+R T \ln \frac{x_{\mathrm{CH}_{4}}}{x_{\mathrm{H}_{2}}^{2}} \\
& \Delta G_{9}=167.59-0.17349 T+\frac{1436.4}{T}+R T \ln \frac{P}{P_{0}}+R T \ln \frac{x_{\mathrm{CO}_{2}}^{2}}{x_{\mathrm{CO}_{2}}} \\
& \Delta G_{10}=137.56-0.14415 T-\frac{936.81}{T}+R T \ln \frac{P}{P_{0}}+R T \ln \frac{x_{\mathrm{CO}_{1}} x_{\mathrm{H}_{2}}}{x_{\mathrm{H}_{2} \mathrm{O}}} \\
& \Delta_{11}=107.52-0.11480 T-\frac{3310.2}{T}+R T \ln \frac{P}{P_{0}}+R T \ln \frac{x_{\mathrm{CO}_{2}} x_{\mathrm{H}_{2}}^{2}}{x_{\mathrm{H}_{2} \mathrm{O}}^{2}}
\end{aligned}
$$

A complete list of stoichiometrically distinct RERs and their stoichiometric factors are presented in Table 1. The Gibbs free energies of the RERs for an ideal gas and pure solid phase (graphite) model as a function of temperature, pressure and composition (mole fractions) are given in Table 2. Data were computed using the commercial software HSC Chemistry® 4.0, Outokumpu.

\section{Overall Stabilities of the Species}

Once the complete list of RERs, their stoichiometric factors and Gibbs free energy changes are known, the overall stabilities of the species are readily evaluated according to eqs 1 and 2 . The results for the C-H-O system are summarized in Table 3.

\section{Overal Stabilities of the Species in the System C-H-O}

$$
\begin{aligned}
& \Sigma_{\mathrm{CH}_{4}}=\frac{1}{74}\left(-\Delta G_{1}-\Delta G_{2}-\Delta G_{3}-\Delta G_{4}+\Delta G_{6}+4 \Delta G_{7}+6 \Delta G_{8}\right) \\
& \Sigma_{\mathrm{H}_{2} \mathrm{O}}=\frac{1}{74}\left(-\Delta G_{1}-2 \Delta G_{2}+2 \Delta G_{4}-\Delta G_{5}-2 \Delta G_{6}-8 \Delta G_{7}-\Delta G_{10}-2 \Delta G_{11}\right) \\
& \Sigma_{\mathrm{CO}}=\frac{1}{74}\left(\Delta G_{1}+2 \Delta G_{3}+4 \Delta G_{4}-\Delta G_{5}+2 \Delta G_{6}+12 \Delta G_{9}+\Delta G_{10}\right) \\
& \Sigma_{\mathrm{CO}_{2}}=\frac{1}{74}\left(\Delta G_{2}-\Delta G_{3}-3 \Delta G_{4}+\Delta G_{5}+4 \Delta G_{7}-6 \Delta G_{9}+\Delta G_{11}\right)
\end{aligned}
$$




$$
\begin{aligned}
& \Sigma_{\mathrm{H}_{2}}=\frac{1}{74}\left(3 \Delta G_{1}+4 \Delta G_{2}+2 \Delta G_{3}+\Delta G_{5}-12 \Delta G_{8}+\Delta G_{10}+2 \Delta G_{11}\right) \\
& \Sigma_{\mathrm{C}}=\frac{1}{74}\left(-3 \Delta G_{6}-8 \Delta G_{7}-6 \Delta G_{8}-6 \Delta G_{9}-\Delta G_{10}-\Delta G_{11}\right)
\end{aligned}
$$

Numerical evaluation of the overall stabilities of species as a function of $T, P$ and composition allows one to determine the species that are stable (formed) or unstable (consumed). For instance, at $T=500^{\circ} \mathrm{K} . P=1$ atm and $x_{\mathrm{CH}_{4}}=x_{\mathrm{H}_{2} \mathrm{O}}=x_{\mathrm{CO}}=x_{\mathrm{CO}_{2}}=x_{\mathrm{H}_{2}}=0.2$ the overall species stabilities are: $\Sigma_{\mathrm{CH}_{4}}=-4.48, \Sigma_{\mathrm{H}_{2} \mathrm{O}}=-5.72, \Sigma_{\mathrm{CO}}=28.91$, $\Sigma_{\mathrm{CO}_{2}}=-11.60, \Sigma_{\mathrm{H}_{2}}=14.68$ and $\Sigma_{\mathrm{C}}=-12.83$. Thus, under these conditions $\mathrm{CH}_{4}, \mathrm{H}_{2} \mathrm{O}, \mathrm{CO}_{2}$ and $\mathrm{C}$ are stable (formed), while $\mathrm{H}_{2}$ and $\mathrm{CO}$ are unstable (consumed). At higher temperatures, e.g., $T=1200^{\circ} \mathrm{K}$, at the same pressure and composition, the overall species stabilities are: $\Sigma_{\mathrm{CH}_{4}}=5.48, \Sigma_{\mathrm{H}_{2} \mathrm{O}}=10.87, \Sigma_{\mathrm{CO}}=-27.56, \Sigma_{\mathrm{CO}_{2}}=8.34, \Sigma_{\mathrm{H}_{2}}=-21.83$ and $\Sigma_{\mathrm{C}}=13.74$. Thus, under these conditions the situation is reversed, i.e., $\mathrm{CH}_{4}, \mathrm{H}_{2} \mathrm{O}, \mathrm{CO}_{2}$ and $\mathrm{C}$ are unstable (consumed), while $\mathrm{H}_{2}$ and $\mathrm{CO}$ are stable (formed). This behavior can be easily rationalized in terms of contributions coming from RERs.

Consider, for example, the overall stability of $\mathrm{H}_{2}$. As can be seen from Table 4, at low temperatures $\left(T=500^{\circ} \mathrm{K}\right)$ all of the RERs involving $\mathrm{H}_{2}$ but one are thermodynamically favored toward consumption of $\mathrm{H}_{2}$

$$
\begin{array}{ll}
\mathrm{CO}+3 \mathrm{H}_{2}=\mathrm{CH}_{4}+\mathrm{H}_{2} \mathrm{O} & \Delta G_{1}=-83.15 \mathrm{~kJ} / \mathrm{mol} \\
\mathrm{CO}_{2}+4 \mathrm{H}_{2}=\mathrm{CH}_{4}+2 \mathrm{H}_{2} \mathrm{O} & \Delta G_{2}=-63.04 \mathrm{~kJ} / \mathrm{mol} \\
2 \mathrm{CO}+2 \mathrm{H}_{2}=\mathrm{CH}_{4}+\mathrm{CO}_{2} & \Delta G_{3}=-103.26 \mathrm{~kJ} / \mathrm{mol} \\
\mathrm{C}+2 \mathrm{H}_{2}=\mathrm{CH}_{4} & \Delta G_{8}=-26.23 \mathrm{~kJ} / \mathrm{mol} \\
\mathrm{CO}+\mathrm{H}_{2}=\mathrm{C}+\mathrm{H}_{2} \mathrm{O} & \Delta G_{10}=-56.92 \mathrm{~kJ} / \mathrm{mol} \\
\mathrm{CO}_{2}+2 \mathrm{H}_{2}=\mathrm{C}+2 \mathrm{H}_{2} \mathrm{O} & \Delta G_{11}=-36.81 \mathrm{~kJ} / \mathrm{mol}
\end{array}
$$

The only RER that, under these conditions, is thermodynamically favored toward the formation of $\mathrm{H}_{2}$ is the water-gas shift reaction

$$
\mathrm{H}_{2} \mathrm{O}+\mathrm{CO}=\mathrm{CO}_{2}+\mathrm{H}_{2} \quad \Delta G_{5}=-20.11 \mathrm{~kJ} / \mathrm{mol}
$$

Overall, however, the $\mathrm{H}_{2}$ consumption reactions are dominant and, hence, under these conditions, $\mathrm{H}_{2}$ is thermodynamically unstable (consumed). As the temperature increases $T=1200^{\circ} \mathrm{K}$ ), the Gibbs free energies of the above reactions change sign (Table 1) thus producing $\mathrm{H}_{2}$ via all RERs

$$
\begin{array}{ll}
\mathrm{CH}_{4}+\mathrm{H}_{2} \mathrm{O}=\mathrm{CO}+3 \mathrm{H}_{2} & \Delta G_{1}=-109.39 \mathrm{~kJ} / \mathrm{mol} \\
\mathrm{CH}_{4}+2 \mathrm{H}_{2} \mathrm{O}=\mathrm{CO}_{2}+4 \mathrm{H}_{2} & \Delta G_{2}=-106.18 \mathrm{~kJ} / \mathrm{mol} \\
\mathrm{CH}_{4}+\mathrm{CO}_{2}=2 \mathrm{CO}+2 \mathrm{H}_{2} & \Delta G_{3}=-112.59 \mathrm{~kJ} / \mathrm{mol} \\
\mathrm{CH}_{4}=\mathrm{C}+2 \mathrm{H}_{2} & \Delta G_{8}=-57.13 \mathrm{~kJ} / \mathrm{mol} \\
\mathrm{C}+\mathrm{H}_{2} \mathrm{O}=\mathrm{CO}+\mathrm{H}_{2} & \Delta G_{10}=-52.26 \mathrm{~kJ} / \mathrm{mol} \\
\mathrm{C}+2 \mathrm{H}_{2} \mathrm{O}=\mathrm{CO}_{2}+2 \mathrm{H}_{2} & \Delta G_{11}=-49.06 \mathrm{~kJ} / \mathrm{mol}
\end{array}
$$

except the reverse water-gas shift reaction

$$
\mathrm{CO}_{2}+\mathrm{H}_{2}=\mathrm{H}_{2} \mathrm{O}+\mathrm{CO} \quad \Delta G_{5}=-3.20 \mathrm{~kJ} / \mathrm{mol}
$$

in which $\mathrm{H}_{2}$ is consumed. Since $\mathrm{H}_{2}$ producing RERs are dominant, $\mathrm{H}_{2}$ is overall stable (formed) under these conditions.

A major problem in steam and carbon dioxide reforming is the deposition of carbon. The carbon formation region may be also easily rationalized in terms of contributions associated with RERs. Thus, employing the data presented in Table 1, it is seen that at low temperatures $\left(T=500^{\circ} \mathrm{K}\right)$ carbon formation is thermodynamically favored in five RERs, namely

$$
\begin{array}{ll}
2 \mathrm{CO}+\mathrm{CH}_{4}=3 \mathrm{C}+2 \mathrm{H}_{2} \mathrm{O} & \Delta G_{6}=-87.61 \mathrm{~kJ} / \mathrm{mol} \\
\mathrm{CO}_{2}+\mathrm{CH}_{4}=2 \mathrm{C}+2 \mathrm{H}_{2} \mathrm{O} & \Delta G_{7}=-10.58 \mathrm{~kJ} / \mathrm{mol} \\
2 \mathrm{CO}=\mathrm{C}+\mathrm{CO}_{2} & \Delta G_{9}=-77.03 \mathrm{~kJ} / \mathrm{mol} \\
\mathrm{CO}+\mathrm{H}_{2}=\mathrm{C}+\mathrm{H}_{2} \mathrm{O} & \Delta G_{10}=-56.92 \mathrm{~kJ} / \mathrm{mol} \\
\mathrm{CO}_{2}+2 \mathrm{H}_{2}=\mathrm{C}(\mathrm{gr})+2 \mathrm{H}_{2} \mathrm{O} & \Delta G_{11}=-36.81 \mathrm{~kJ} / \mathrm{mol}
\end{array}
$$


versus only one RER that is thermodynamically favorable toward carbon consumption

$$
\mathrm{C}(\mathrm{gr})+2 \mathrm{H}_{2}=\mathrm{CH}_{4} \quad \Delta G_{8}=-26.23 \mathrm{~kJ} / \mathrm{mol}
$$

Overall, however, at low temperatures $\left(T=500^{\circ} \mathrm{K}\right)$ the carbon formation reactions are dominant. As the temperature increases $\left(T=1200^{\circ} \mathrm{K}\right)$, four of the RERs become thermodynamically favorable toward consumption of carbon, namely carbon gasification

$$
\begin{array}{ll}
3 \mathrm{C}+2 \mathrm{H}_{2} \mathrm{O}=2 \mathrm{CO}+\mathrm{CH}_{4} & \Delta G_{6}=-47.39 \mathrm{~kJ} / \mathrm{mol} \\
\mathrm{C}+\mathrm{CO}_{2}=2 \mathrm{CO} & \Delta G_{9}=-55.46 \mathrm{~kJ} / \mathrm{mol} \\
\mathrm{C}+\mathrm{H}_{2} \mathrm{O}=\mathrm{CO}+\mathrm{H}_{2} & \Delta G_{10}=-52.26 \mathrm{~kJ} / \mathrm{mol} \\
\mathrm{C}+2 \mathrm{H}_{2} \mathrm{O}=\mathrm{CO}_{2}+2 \mathrm{H}_{2} & \Delta G_{11}=-49.06 \mathrm{~kJ} / \mathrm{mol}
\end{array}
$$

while in the two remaining RERs

$$
\begin{array}{ll}
\mathrm{CO}_{2}+\mathrm{CH}_{4}=2 \mathrm{C}+2 \mathrm{H}_{2} \mathrm{O} & \Delta G_{7}=-8.07 \mathrm{~kJ} / \mathrm{mol} \\
\mathrm{CH}_{4}=\mathrm{C}+2 \mathrm{H}_{2} & \Delta G_{8}=-57.13 \mathrm{~kJ} / \mathrm{mol}
\end{array}
$$

carbon is formed. Overall, as can be easily verified from the stoichiometry and thermodynamics of the RERs, the carbon consuming RERs are dominant at the higher temperatures.

\section{Graphical Representation of the Overall Species Stabilities}

The overall stability relations may be best visualized by plotting the equilibrium lines of the overall stabilities of the species in various coordinates. As an example, consider the overall stability of carbon (graphite). Employing the relations in Tables 2 and 3, the following expression is generated for the overall stability relation for carbon (graphite)

$$
\begin{aligned}
& \Sigma_{\mathrm{C}}=-17.44+0.01589 T-\frac{519.26}{T}-\frac{5 R T}{74} \ln \frac{P}{P_{0}}-\frac{17 R T}{74} \ln x_{\mathrm{CH}_{4}} \\
& +\frac{25 R T}{74} \ln x_{\mathrm{H}_{2} \mathrm{O}}-\frac{19 R T}{74} \ln x_{\mathrm{CO}}-\frac{3 R T}{74} \ln x_{\mathrm{CO}_{2}}+\frac{9 R T}{74} \ln x_{\mathrm{H}_{2}}
\end{aligned}
$$

The surface $\Sigma_{\mathrm{C}}\left(T, P, x_{\mathrm{CH}_{4}}, x_{\mathrm{H}_{2} \mathrm{O}}, x_{\mathrm{CO}}, x_{\mathrm{CO}_{2}}, x_{\mathrm{H}_{2}}\right)=0$ separates the space $\left(T, P, x_{\mathrm{CH}_{4}}, x_{\mathrm{H}_{2} \mathrm{O}}, x_{\mathrm{CO}}, x_{\mathrm{CO}_{2}}\right.$ and $\left.x_{\mathrm{H}_{2}}\right)$ into a stable $\left(\Sigma_{C}<0\right)$, unstable $\left(\Sigma_{C}>0\right)$ and equilibrium $\left(\Sigma_{C}=0\right)$ field. For instance, at constant, equimolar composition of the gas phase, i.e., $x_{\mathrm{CH}_{4}}=x_{\mathrm{H}_{2} \mathrm{O}}=x_{\mathrm{CO}}=x_{\mathrm{CO}_{2}}=x_{\mathrm{H}_{2}}=0.2$, the $T$, $P$ carbon deposition boundary is given by

$-17.4388-519.296 / T+0.016795 T-0.001292 T \log P=0$

This line is depicted graphically in Figure 1. Further, it is evident from eq 3 that $\mathrm{CH}_{4}, \mathrm{CO}$ and $\mathrm{CO}_{2}$ aid in the formation of $\mathrm{C}$, while $\mathrm{H}_{2} \mathrm{O}$ and $\mathrm{H}_{2}$ deter it, especially $\mathrm{H}_{2} \mathrm{O}$.

A complete graphical representation of the equilibrium surfaces (lines) for all species is, of course, not practical. It is more useful to plot regions in which the overall stability of a given species is dominant. Such type of graphical construction may be referred to as "overall predominance diagrams" and may be constructed based on the following considerations:

A) A species, say $\mathrm{B}_{p}$, is dominant in a certain region if its overall stability $\Sigma_{p}$ in this region is non-positive and lower than the overall stability of any other species.

b) The stability regions of two species, say $\mathrm{B}_{p}$ and $\mathrm{B}_{q}$, are separated by a line, called predominance line, such that the overall stabilities of $\mathrm{B}_{p}$ and $\mathrm{B}_{q}$ at each point on this line are non-positive and equal, i.e., $\Sigma_{p}=\Sigma_{q}$. A predominance line separating the stability regions of two species $\mathrm{B}_{p}$ and $\mathrm{B}_{q}$ is stable if their overall stabilities on the predominance line are non-positive, equal and lower than the overall stabilities of any other species.

c) The stability regions of three species, say $\mathrm{B}_{p}, \mathrm{~B}_{q}$ and $\mathrm{B}_{r}$, intersects at a point, called the triple point, such that the overall stability of the species $\mathrm{B}_{p}, \mathrm{~B}_{q}$ and $\mathrm{B}_{r}$ at this point are non-positive and equal, i.e., $\Sigma_{\mathrm{B}_{p}}=\sum_{\mathrm{B}_{q}}=\Sigma_{\mathrm{B}_{r}}$. A triple point is stable if the overall stabilities of the species $\mathrm{B}_{p}, \mathrm{~B}_{q}$ and $\mathrm{B}_{r}$ at this point are non-positive, equal and lower than the overall stabilities of all other species. 


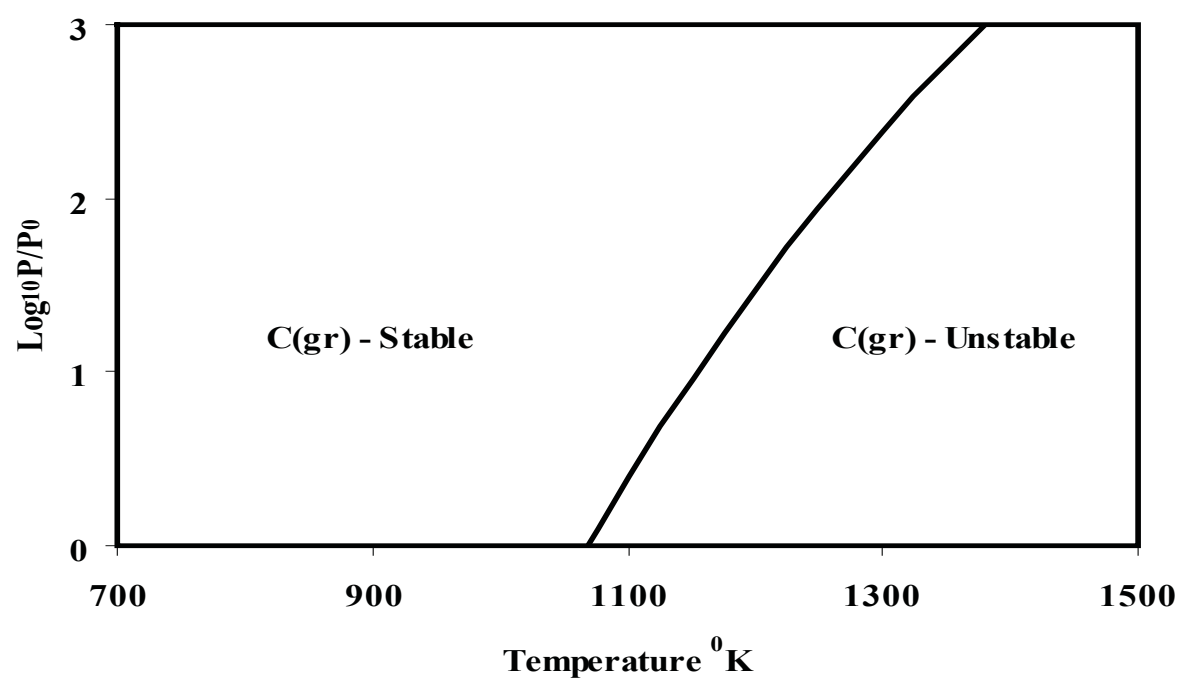

Figure 1. Overall stability boundary of $\mathrm{C}(\mathrm{gr})$ for equimolar composition of the gas phase

The easiest way to construct an overall predominance diagram is to generate first the stable triple points. Once the location of the stable triple points is known, the final topology of the stability regions of the species may be deduced by determining the stable predominance lines.

Next, we illustrate the approach by constructing an overall predominance diagram in the coordinates $T-P$ at equimolar composition of the gas phase species. For these particular conditions, the overall species stabilities are

$$
\begin{aligned}
& \sum_{\mathrm{CH}_{4}}=-18.7462+539.057 / T+0.0239731 T-0.00335931 T \log P \\
& \sum_{\mathrm{H}_{2} \mathrm{O}}=-10.2556+338.492 / T+0.0112517 T-0.00180886 T \log P \\
& \Sigma_{\mathrm{CO}}=62.1143+298.97 / T-0.0702836 T+0.00749384 T \log P \\
& \Sigma_{\mathrm{CO}_{2}}=-25.9293-318.731 / T+0.029516 T-0.00284249 T \log P \\
& \sum_{\mathrm{H}_{2}}=47.748-1416.61 / T-0.0591979 T+0.00852747 T \log P \\
& \Sigma_{\mathrm{C}}=-17.4388-519.296 / T+0.0167945 T-0.00129204 T \log P
\end{aligned}
$$

For the $\mathrm{CH}_{4}(\mathrm{~g})-\mathrm{H}_{2} \mathrm{O}(\mathrm{g})-\mathrm{CO}(\mathrm{g})-\mathrm{CO}_{2}(\mathrm{~g})-\mathrm{H}_{2}(\mathrm{~g})-\mathrm{C}(\mathrm{gr})$ system the number of possible triple points is equal to the number of ways three species may be selected from a total of six, i.e., $6 ! / 3 ! / 3 !=20$. Consider, for instance, the position of the triple point $\mathrm{CH}_{4}-\mathrm{H}_{2} \mathrm{O}-\mathrm{CO}_{2}$. Solving simultaneously the equations $\sum_{\mathrm{CH}_{4}}=\Sigma_{\mathrm{H}_{2} \mathrm{O}}=\sum_{\mathrm{CO}_{2}}$ gives $T=1097.2^{0} \mathrm{~K}$ and $\log P=3.3$. The overall stabilities of the species at this point are

$$
\begin{array}{ll}
\sum_{\mathrm{CH}_{4}}=-4.2 \mathrm{~kJ} / \mathrm{mol} & \sum_{\mathrm{CO}_{2}}=-4.2 \mathrm{~kJ} / \mathrm{mol} \\
\sum_{\mathrm{H}_{2} \mathrm{O}}=-4.2 \mathrm{~kJ} / \mathrm{mol} & \sum_{\mathrm{H}_{2}}=12.6 \mathrm{~kJ} / \mathrm{mol} \\
\sum_{\mathrm{CO}}=12.6 \mathrm{~kJ} / \mathrm{mol} & \sum_{\mathrm{C}}=-4.2 \mathrm{~kJ} / \mathrm{mol}
\end{array}
$$

As can be seen, it so happens that the overall stabilities of four species $\mathrm{CH}_{4}, \mathrm{H}_{2} \mathrm{O}, \mathrm{CO}_{2}$ and $\mathrm{C}$ (gr) are equal, negative and lower than the overall stabilities of the remaining two species at this point. In fact, this means that four triple points, namely, $\mathrm{CH}_{4}-\mathrm{H}_{2} \mathrm{O}-\mathrm{CO}_{2}, \mathrm{CH}_{4}-\mathrm{H}_{2} \mathrm{O}-\mathrm{C}(\mathrm{gr}), \mathrm{CH}_{4}-\mathrm{CO}_{2}-\mathrm{C}$ (gr) and $\mathrm{H}_{2} \mathrm{O}-\mathrm{CO}_{2}-\mathrm{C}$ (gr) coincide and all of them are stable. 


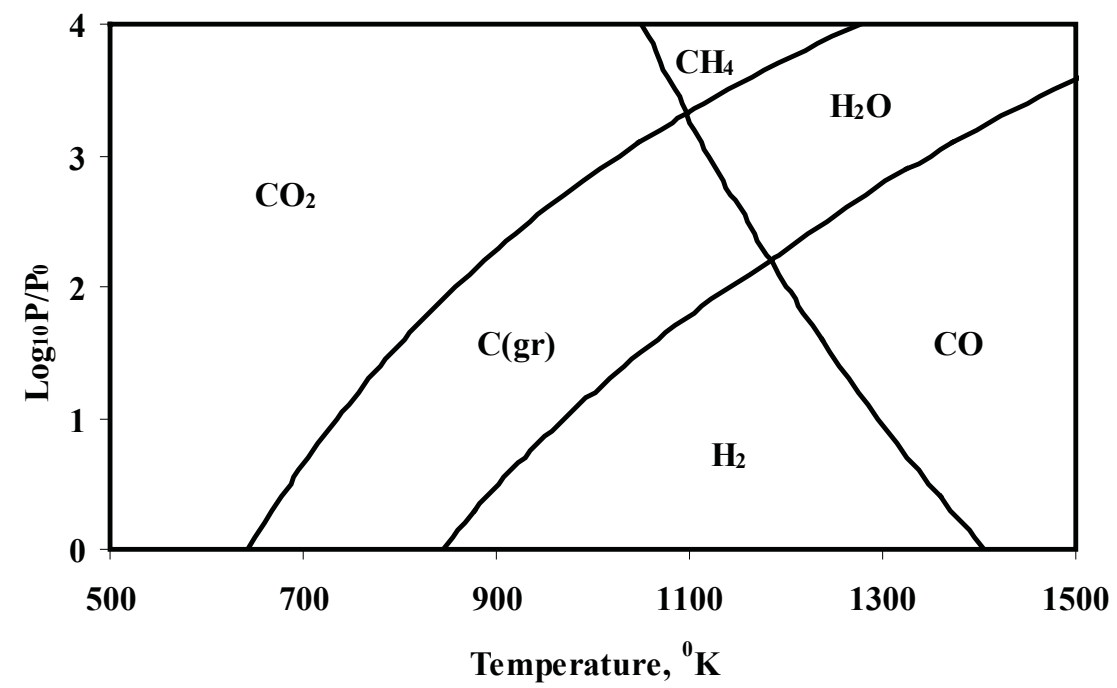

Figure 2. Overall stability predominance diagram for the system C-H-O for equimolar composition of the gas phase

Consider next the triple point $\mathrm{CO}-\mathrm{CO}_{2}-\mathrm{C}(\mathrm{gr})$. The solution of $\Sigma_{\mathrm{CO}}=\Sigma_{\mathrm{CO}_{2}}=\Sigma_{\mathrm{C}(\mathrm{gr})}$ is $T=2157.9$ and $\log$ $P=5.7$. At this $T$ and $P$ the overall stabilities of the species are

$$
\begin{array}{ll}
\Sigma_{\mathrm{CH}_{4}}=-8.0 \mathrm{~kJ} / \mathrm{mol} & \sum_{\mathrm{CO}_{2}}=2.7 \mathrm{~kJ} / \mathrm{mol} \\
\sum_{\mathrm{H}_{2} \mathrm{O}}=-8.0 \mathrm{~kJ} / \mathrm{mol} & \sum_{\mathrm{H}_{2}}=24.1 \mathrm{~kJ} / \mathrm{mol} \\
\Sigma_{\mathrm{CO}}=2.7 \mathrm{~kJ} / \mathrm{mol} & \Sigma_{\mathrm{C}}=2.7 \mathrm{~kJ} / \mathrm{mol}
\end{array}
$$

Since the overall stabilities of $\mathrm{CO}, \mathrm{CO}_{2}$ and $\mathrm{C}(\mathrm{gr})$ are positive, this triple point is unstable and should not appear on the diagram. Continuing the above procedure over the remaining triple points shows that four more triple points, namely, $\mathrm{H}_{2} \mathrm{O}-\mathrm{CO}-\mathrm{H}_{2}, \mathrm{H}_{2} \mathrm{O}-\mathrm{CO}-\mathrm{C}(\mathrm{gr}), \mathrm{H}_{2} \mathrm{O}-\mathrm{H}_{2}-\mathrm{C}(\mathrm{gr})$ and $\mathrm{CO}-\mathrm{H}_{2}-\mathrm{C}(\mathrm{gr})$, are stable and they coincide. Hence, only 2 distinct intersections should appear in the predominance diagram. The final overall predominance diagram is presented in Figure 2.

\section{Concluding Remarks}

The equilibrium composition of a multiple chemical reaction system is a complex function of the thermodynamic variables. Except for the case of a single chemical reaction system, the prediction and rationalization of the system's response to a change in variables may be obtained only via numerical simulation of the equilibrium composition which is difficult to interpret. In this respect, the overall species stability approach in multiple chemical reaction systems discussed above may be viewed as the generalization of the simple thermodynamic principle valid for a single chemical reaction system. Thus, the overall stabilities of the species in a multiple chemical reaction system may be partitioned into a linear sum of contributions associated with distinct RERs, such that each individual term retains the same mathematical form as that valid for a single reaction system. In this work, we applied this new approach to the analysis of stability relations in the $\mathrm{C}-\mathrm{H}-\mathrm{O}$ system. The overall stabilities of the species generated here are shown to be useful in predicting and rationalizing the system's behavior as a function of pressure, temperature and composition.

\section{References}

[1]. Sandler, S. I. Chemical and Engineering Thermodynamics; John Wiley \& Sons, New York, 1999.

[2]. Smith, J. M.; Van Ness, H. C.; Abbot, M. M. Introduction to Chemical Engineering Thermodynamics; McGraw Hill, NY, 2005.

[3]. Smith, W. R.; Missen, R. W. Chemical Reaction Equilibrium Analysis: Theory and Algorithms; John Wiley \& Sons; New York, 1982.

[4]. Cairns, E. J.; Tevebaugh, A. D. CHO Gas Phase Compositions in Equilibrium with Carbon, and Carbon Deposition Boundaries at One Atmosphere. J. Chem. Eng. Data, 1964, 9, 453. 
[5]. Tevebaugh, A. D.; Cairns, E. J. Carbon Deposition Boundaries in the CHO System at Several Pressures. J. Chem. Eng. Data, 1965, 10, 359 .

[6]. Mohnot, S.; Kyle, B. G. Equilibrium Gas-Phase Compositions and Carbon Deposition Boundaries in the CHOInert System. Ind. Eng. Chem. Proc. Des. Dev. 1978, 17, 270.

[7]. Fishtik, I.; Datta, R. A General Thermodynamic and Stoichiometric Theory of Stability of Chemical Species. $J$. Phys. Chem. A. 2004, 108, 5727.

[8]. Fishtik, I. Thermodynamic Stability of Chemical Species in Multiple Reaction Systems. J. Phys. Chem. B. 2005, 109, 3851.

[9]. Fishtik, I; Gutman, I; Nagypal, I. Response Reactions in Chemical Thermodynamics. J. Chem. Soc. Faraday Trans. 1996, 92, 3525. 